\title{
A Case Report of Idiopathic Giant Cell Myocarditis
}

Bao Bui, MD, Sumeet Chhabra, MD, Siva K. Kumar, MD

\section{Case Report}

A 32 year old African American male was admitted to an outside hospital in July 2007 with symptoms of severe heart failure that required implantation of a short-term left ventricular assist device (LVAD). He was subsequently transferred to our facility due to worsening left ventricular heart failure, episodes of Torsades de Pointes, and monomorphic ventricular tachycardia. His device was replaced with a longer-term LVAD and he was discharged home in October. Fortunately, he underwent successful orthotopic heart transplant in November 2007.

Surgical pathology of the explanted heart revealed widespread cardiomyocyte necrosis, marked polymorphous inflammation, and giant cell formation consistent with idiopathic giant cell myocarditis (figures). Follow-up post transplant endomyocardial biopsies did not reveal recurrence of giant cell myocarditis or acute rejection.

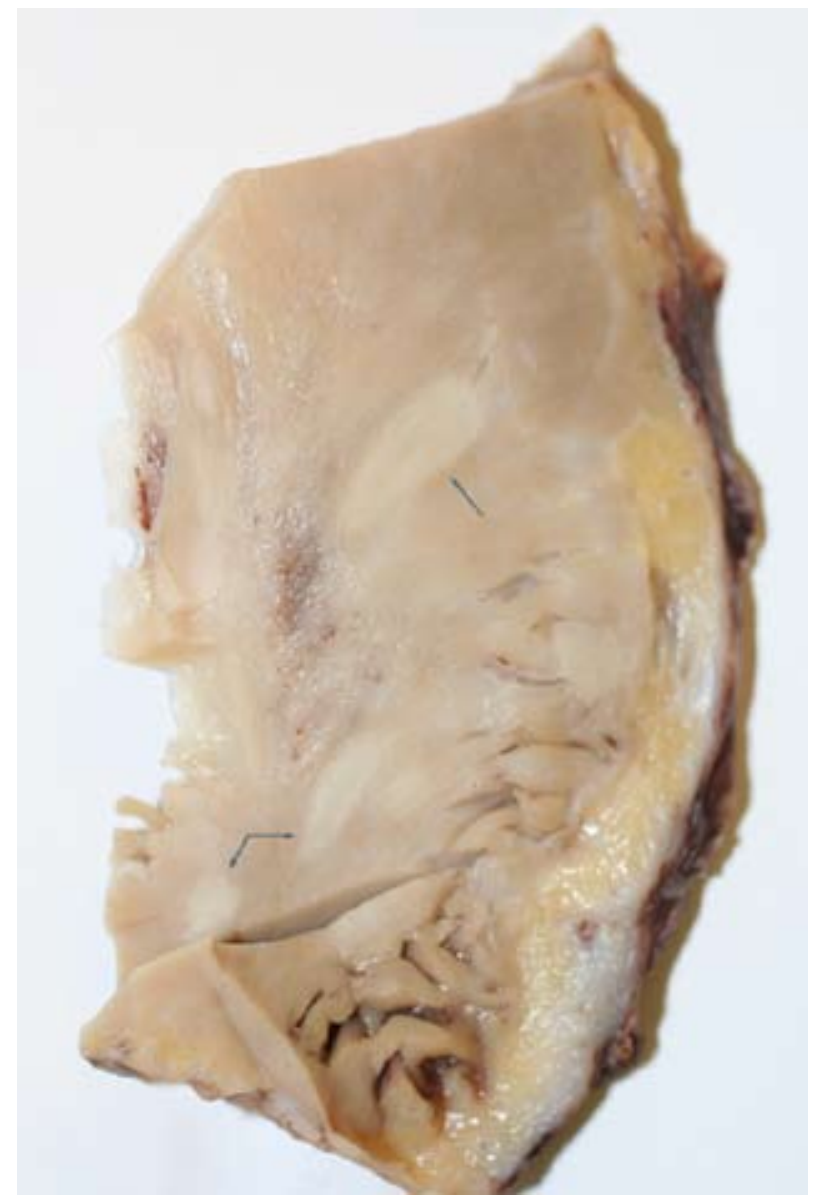

Figure 1. Grossimage ofleft ventricularmyocardium showing nodular, ovoid tan-white areas (indicated by arrows) that microscopically corresponded to the areas of inflammatory cell infiltration and myocyte necrosis.

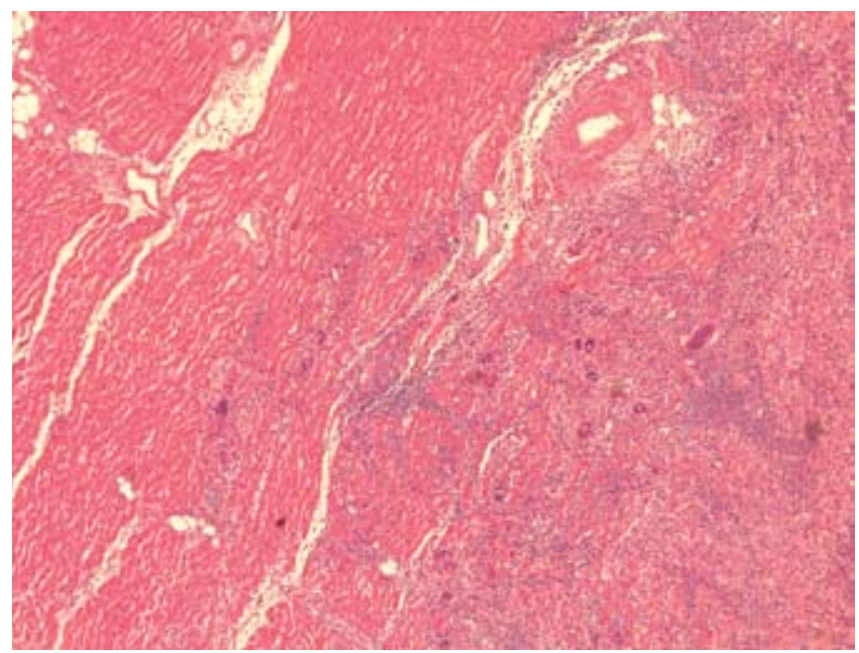

Figure 2. Low power image (40x, H\&E) showing clear delineation of involved areas with inflammatory cell infiltration, giant cells, and myocyte damage compared to relatively unaffected myocardium on the left.

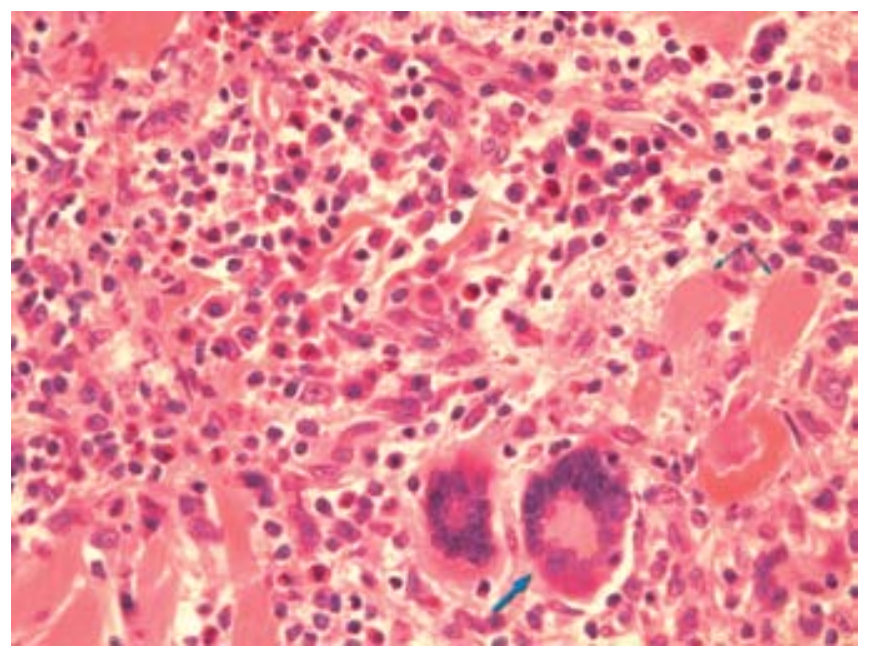

Figure 3. High power image (400x, H\&E) showing a mixed inflammatory cell infiltrate composed of eosinophils, plasma cells, small lymphocytes, and multinucleated giant cells. Prototypical multinucleated giant cell indicated by large thick arrow. Thinner arrow shows associated myocyte damage.

\section{Discussion}

Idiopathic Giant Cell Myocarditis (IGCM) is a rare and generally fatal entity that has been largely confined to scattered case reports and observational studies, most notably a multi-center registry created by Cooper et al in 1997. While IGCM has historically been a histological diagnosis at autopsy, the current gold standard method of diagnosis remains endomyocardial biopsy. This 
disorder typically afflicts younger adults with mean age of fortythree. ${ }^{2}$ It is most commonly characterized by rapid and progressive congestive heart failure generally refractory to conventional heart failure treatments. Other common clinical presentations include ventricular arrhythmias, heart block, and less commonly as early symptoms of acute myocardial infarction.

While no uniform guidelines yet exist for the treatment of IGCM, animal models suggest involvement of CD4 T-lymphocytes ${ }^{5,9}$ with reported success with combined steroid and immunosuppressive therapy. ${ }^{2,3}$ Reported associations with autoimmune disorders are also consistent with this theory. ${ }^{1,6}$

Patients in the IGCM registry that received immunosuppression lived longer than those that did not. ${ }^{2}$ Heart transplantation also appeared to be efficacious with 5-year survival data reported at $71 \%$ despite recurrence of disease in $20-42 \%$ of the newly transplanted hearts. ${ }^{2,4}$ Our case of IGCM illustrates the importance of surveillance biopsies and the growing evidence that transplantation and immunosuppression may be effective therapy for an otherwise rapidly fatal disease.

\section{References}

1. Burke, J, Medline, N, Katz, A. Giant cell myocarditis and myositis associated with thymoma and myasthenia gravis. Archives of Pathology 1969; 88:359.

2. Cooper, LT, Berry, GJ, Shabetai, R. Idiopathic giant cell myocarditis: natural history and treatment. N Engl J Med 1997; 336:1860.

3. Cooper, L and Okura, Y. Idiopathic Giant Cell Myocarditis (Opinion Statement) Current Treatment Options in Cardiovascular Medicine 2001; 3:463.

4. Davies, RA, Veint, JP, Smith, S, et al. Giant cell myocarditis: clinical presentation, bridge to transplantation with mechanical circulatory support, and long-term outcome. J Heart Lung Transplant 2002; 21:674.

5. Kodoma, M, Matsumoto, Y, Fujiwara, M, et al. Characteristics of giant cells and factors related to the formation of giant cells in myocarditis. Circ Res 1991; 69(4):1042.

6. Langston, J, Wagman, G, Dickenman, R. Granulomatous myocarditis and myositis associated with thymoma. Archives of Pathology 1959; 68:367.

7. Menghini, V, Savcenko, V, Olson, L, et al. Combined immunosuppression for the treatment of idiopathic giant cell myocarditis. Mayo Clin Proc. 1999; 74(12):1221-6.

8. Scott, RL, Ratliff, NB, Starling, RC, et al. Recurrence of giant cell myocarditis in cardiac allograft. J Heart Lung Transplant 2001; 20:375.

9. Zhang, S, Kodoma, M, Hanawa, H, et al. Effects of cyclosporine, prednisolone and aspirin on rat autoimmune giant cell myocarditis. J Am Coll Cardiol 1993; 21(5):1254. 